\title{
Clinical Significance of Discordances in Sentinel Lymph Node Reactivity Between Radioisotope and Indocyanine Green Fluorescence in Patients With cNO Breast Cancer Patients
}

Kenjiro Jimbo ( $\sim$ kjimbo@ncc.go.jp )

National Cancer Center Hospital, Japan https://orcid.org/0000-0002-3919-5170

Uta Nakadaira

National Cancer Center Hospital, Japan

Chikashi Watase

National Cancer Center Hospital, Japan

Takeshi Nurata

National Cancer Center, Japan

Sho Shiino

National cancer center hospital, japan

Shin Takayama

National cancer center hospital, Japan

Akihiko Suto

National cancer hospital, Japan

\section{Research Article}

Keywords: radioisotopes, indocyanine green fluorescence, sentinel lymph node biopsy

Posted Date: October 25th, 2021

DOI: https://doi.org/10.21203/rs.3.rs-831829/v1

License: (a) (i) This work is licensed under a Creative Commons Attribution 4.0 International License.

Read Full License

Version of Record: A version of this preprint was published at Asian Journal of Surgery on April 1st, 2022. See the published version at https://doi.org/10.1016/j.asjsur.2022.03.075. 


\section{Abstract}

Background: To evaluate the usefulness of combining radioisotopes and indocyanine green (ICG) and investigate discordances in sentinel lymph node $(\mathrm{SN})$ reactivity using each tracer in cNO breast cancer patients.

Methods: 338 cN0 primary breast cancer patients who underwent SN biopsy with radioisotopes and ICG and axillary lymph node (ALN) dissection were included. SN positivities with radioisotopes, ICG, and both were denoted as $\mathrm{SN}(\mathrm{RI}), \mathrm{SN}(\mathrm{ICG})$, and $\mathrm{SN}(\mathrm{RI}+\mathrm{ICG})$, respectively. We retrospectively estimated metastatic $\mathrm{SN}$ detection rates, each method's discordance rate, and correlation of discordances in SN reactivity with postoperative $\mathrm{N}$ staging.

Results: The combination of radioisotopes and ICG had higher metastatic SN detection rates (99.7\%) than radioisotopes or ICG alone ( $91.7 \%$ and $96.4 \%$, respectively; $p<0.01)$. The discordance rate between $\mathrm{SN}(\mathrm{RI})$ (11 cases) and SN(ICG) (27 cases) in detecting metastatic SNs was $11.2 \%$. The absence of SN(RI), cT stage (cT2-3), higher histological grade, and histological type were identified as risk factors of pN2-3 disease (odds ratios: $8.64,2.56,1.92$, and 3.28 , respectively; $p<0.01$ ).

Conclusions: Discordances in SN reactivity between radioisotopes and ICG helps identify SN metastasis. Although the absence of $\mathrm{SN}(\mathrm{RI})$ is rare, it is a significant sign of advanced ALN metastases; ALN dissection should be considered for accurate nodal staging.

\section{Introduction}

Sentinel lymph node (SN) biopsy (SNB) is an axillary nodal staging method widely used in clinically nodenegative (CNO) patients with breast cancer. If tumor cells are present in SNs, axillary lymph node (ALN) dissection (ALND) has long been recommended for the purpose of local control and further staging of ALN. Although postoperative treatment of breast cancer mainly depends on the intrinsic subtype, the ALN metastatic status also has a great influence on the treatment choice and intensity. Therefore, accurate ALN staging ( $\mathrm{N}$ staging) is essential for therapeutic decision-making, and the ALN metastatic status can only be correctly assessed using ALND currently. However, in recent years, the oncological safety of longtime follow-up of omitting ALND even if metastasis is observed in SN under certain conditions has been proved [1, 2]; therefore, ALND is no longer the gold standard. Furthermore, since ALND may cause side effects, such as lymphedema and numbness of the ipsilateral upper limbs compared with SNB [3], the trend of axillary therapeutic management in patients with SN metastasis has gradually shifted to the strategy of omitting unnecessary ALND [4]. In contrast, omitting ALND may result in underestimation of N staging in some cases. Most patients with intraoperative SN metastases are eventually diagnosed with pN1 after ALND; therefore, ALND is not strongly required in such cases because the significance of local control is relatively low in pN1 and the treatment options do not change with or without ALND. However, some patients with cNO may unexpectedly be diagnosed with pN2-3 after ALND and may need intensive postoperative adjuvant treatment. Therefore, it is important to not overlook metastatic SNs and properly 
select cases that will benefit from ALND in SNB. If we can predict advanced ALN metastasis (cN2-3) in cNO cases with SNB, we can appropriately select patients who really need ALND and obtain accurate nodal information.

Radioisotope (RI) and indocyanine green (ICG) are both standard tracers in SNB and have the same high SN detection rate [5-7]. There are some reports on the utility of the combination of RI and ICG [5, 8-10]. However, there are some discordances in the reactivity of each SN between the two methods, and the correlation of discordances in $\mathrm{SN}$ reactivity with the postoperative $\mathrm{N}$ staging has not been fully investigated. Therefore, in this study, we aimed to retrospectively evaluate the usefulness of the combination of RI and ICG and the clinical significance of the discordances in SN reactivity between RI and ICG in patients with cNO breast cancer in identifying the patients who really require ALND.

\section{Patients And Methods}

\section{Patients and definitions}

This study included 338 consecutive patients with cN0 primary breast cancer who underwent SNB using RI and ICG concurrently and ALND between January 2011 and April 2018 at the National Cancer Center Hospital in Tokyo, Japan. Patients who underwent ipsilateral breast surgery previously and male patients were excluded. The study was conducted in accordance with the Declaration of Helsinki (as revised in 2013). The study was approved by the institutional ethics committee of the National Cancer Center Hospital in Tokyo, Japan.

We defined resected SNs that react to $\mathrm{RI}$ as $\mathrm{SN}(\mathrm{RI})$ (independent of ICG reactivity) and SNs that react to ICG as SN(ICG) (independent of RI reactivity). Furthermore, we defined resected SNs that react to both RI and ICG as SN(RI+ICG).All data of clinical findings were obtained from the clinical documents. Clinical and pathological $\mathrm{T}$ and $\mathrm{N}$ factors were based on the Cancer Staging Manual of the American Joint Committee on Cancer, $8^{\text {th }}$ edition [11]. For the cut-off value for estrogen receptor (ER) positivity, we used an immunohistochemistry score (Allred score) and defined ER-positive as proportional score (PS) $>2$ and intensive score (IS) $>1$ (corresponding to more than 1\% ER-positive cells) by the Allred score [12]. HER2 positivity was defined as HER2 score $>3$ ( $>30 \%$ strong membrane immunoreaction-positive cells) or HER 2 gene/centromere-17 ratio $\geq 2.0$ on fluorescent in situ hybridization.

\section{SNB procedure and detection of SNs}

Details of our procedure have been described previously [13]. In brief, SNB was performed by staff surgeons who specialized in breast surgery. Radiotracer (99mTc-phytate in RI) and indocyanine green (ICG) were used as tracers. RI was injected on the day of surgery or the day before the surgery (328 patients received RI on the day before surgery and 4 received it on the day of surgery). In 328 patients who received RI injection on the day of the surgery, lymphoscintigraphy was performed $3 \mathrm{~h}$ after the injection. At the time of the surgery, $1 \mathrm{~mL}$ ICG was injected into the peritumoral space or the areola. Lymph nodes that reacted to a gamma probe were considered $\mathrm{SN}(\mathrm{RI})$ and those that reacted to near- 
infrared light were considered SN(ICG). Excised SNs were cut into 2-mm slices along the short axis and were alternately prepared for one-step nucleic acid amplification (OSNA) and/or histological examination. The sliced tissue specimens for histological examination were first subjected to intraoperative frozensection diagnosis and were then subjected to permanent-section diagnosis. If metastasis was confirmed by either OSNA or histological examination, it was considered SN metastasis.

We compared the resected number of $\mathrm{SNs}$, $\mathrm{SN}$ identification rate per patient, and metastatic $\mathrm{SN}$ detection rate per patient among $S N(R I+I C G), S N(R I)$, and $S N(I C G)$. Subsequently, we estimated the concordance and discordance rates between $\mathrm{SN}(\mathrm{RI})$ and $\mathrm{SN}(\mathrm{ICG})$. Furthermore, we identified the risk factors of advanced nodal involvement based on the preoperative and postoperative findings using a logistic regression model.

\section{Statistical analysis}

We used the Mann-Whitney $U$ test to compare the resected number of $S N s$ between $S N(R I+I C G), S N(R I)$, and $\mathrm{SN}(\mathrm{ICG})$ cases and the age between patients in the pN1 and pN2-3 groups. We used the $\chi 2$ test to compare other variables and logistic regression analyses to investigate the odds ratios of the individual parameters in predicting pN2-3. A $p$-value $<0.05$ was considered statistically significant. Confidence intervals were set at 95\%. SPSS v27 (IBM, Armonk, NY) was used for all statistical analyses.

\section{Results}

\section{Comparison of SNB results}

Table 1 summarizes the outcomes of SNB in each method. Of 338 patients, 337 patients had metastatic SNs and subsequently underwent ALND. One patient had no reaction with either RI or ICG, and ALND was performed to confirm metastatic status. $\mathrm{SN}(\mathrm{RI}), \mathrm{SN}(\mathrm{ICG})$, or $\mathrm{SN}(\mathrm{RI}+\mathrm{ICG})$ was observed in 337 patients (99.7\%). SN(RI) was identified in 331 (97.9\%) patients and SN(ICG) was identified in 334 (98.8\%) patients. There was no significant difference between the three methods in $\mathrm{SN}$ identification rate.

The average number of resected SNs per patient was 2.78 using SN(ICG) and 2.05 using SN(RI) $(p<0.01)$. The metastatic $S N$ detection rate per patient was the highest with $S N(R I+I C G)(99.7 \%)$ compared with the other methods (RI, 91.7\%; ICG, 96.4\%; $p<0.01)$.

Table 2 summarizes the concordance and discordance of metastatic SN detection per patient between SN(RI) and SN(ICG) methods. Of 338 patients, 299 patients with metastatic SNs had positive SN reactions to both RI and ICG, while no reaction was observed in 1 patient. In contrast, 11 patients had metastatic SNs that reacted to only RI and 27 patients had metastatic SNs that reacted to only ICG. The concordance and discordance rates of detecting metastatic SNs between SN(RI) and SN(ICG) were 88.8\% $([299+1] / 338)$ and $11.2 \%([27+11] / 338)$, respectively.

\section{Details of discordant cases}


Table 3 summarizes the rates of $\mathrm{SN}(\mathrm{RI})$ and $\mathrm{SN}(\mathrm{ICG})$ in discordant cases and findings of lymphoscintigraphy. Of the 27 patients in whom metastatic SNs could not be detected by RI, 8 patients had unconfirmed SN reaction to RI. Furthermore, 7 of these 8 patients had no findings of $99 \mathrm{mTc}$ accumulation (hot spots) in the axillary area on lymphoscintigraphy (Fig. 1a), while only a weak hot spot was observed in 1 patient. All other 19 patients in whom metastatic SNs could not be detected using RI had strong hot spots in the axillary area on lymphoscintigraphy (Fig. 1b), and all the patients in whom SNs showed a reaction to RI were confirmed to have metastatic SNs. Of the 11 patients in whom metastatic SNs could not be detected using ICG, SN(ICG) was not confirmed in 3 patients, and all 11 patients had hot spots in the axillary area on lymphoscintigraphy.

\section{Correlation between nodal staging and clinicopathological features}

The clinical and pathological characteristics of all patients are summarized in Table 4. Among 338 patients, 276 were diagnosed with pN1 (total metastatic LNs, 1-3) and 62 with pN2-3 (total metastatic LNs, 4 or more). The overall median age was 54.1 years. Furthermore, 287 patients had invasive ductal carcinoma and 51 had special types of invasive carcinoma (invasive lobular carcinoma, ILC, 40; invasive micropapillary carcinoma, IMPC, 6; metaplastic carcinoma, 3; and apocrine carcinoma, APO, and mucinous carcinoma, MUC, 1). To investigate the difference between pN2-3 status and pN1 status, univariate analyses using the $\chi^{2}$ test were performed with each explanatory variable. Although discordance between $S N(R I)$ and $S N(I C G)$ was not associated with pN2-3 in this analysis $(p=0.647)$, the absence of $\mathrm{SN}(\mathrm{RI})$ was significantly associated with $\mathrm{pN2}-3$ status $(\mathrm{p}<0.01)$. Additionally, cT2-3 stage $(p<0.01)$, histological type $(p<0.01)$, higher histological grade $(G 3)(p=0.015)$, and type of surgery (mastectomy) $(p<0.01)$ were significantly associated with pN2-3 status.

\section{Multivariate logistic regression analyses of pN2-3}

The variables in univariate analysis that significantly $(\mathrm{p}<0.05)$ correlated with $\mathrm{pN} 2-3$ status were analyzed using multivariate logistic analysis. To avoid multicollinearity, we excluded the type of surgery in this analysis. Similar to the findings of univariate analysis, the absence of $S N(R I)$ (odds ratio, 8.64; $p<0.01$ ), cT2-3 stage (odds ratio, 2.549; $p<0.01$ ), histological type (odds ratio, 3.276; $p<0.01$ ), and higher histological grade (G3) (odds ratio, 1.921; $p=0.039$ ) were significantly associated with pN2-3 status (Table 5).

\section{Discussion}

In our results, although there was no significant difference among the three methods in terms of overall SN identification rate, the combined method, including RI and ICG, had a significantly higher metastatic $\mathrm{SN}$ detection rate than methods using RI or ICG alone. This is largely consistent with the results of previous studies [10]. This is mainly due to the discrepancies between the two methods, which compensated for each other's false negatives successfully. In this study, 27 and 11 patients with metastatic SNs were wrongly diagnosed as node-negative by RI and ICG alone, respectively. By using the 
combination method, accurate nodal staging was performed in 38 patients without missing lymph node metastases. Therefore, we were able to avoid false negatives in $38(11.2 \%)$ patients and the discordances in $\mathrm{SN}$ reactivity helped in avoiding the overlooking of $\mathrm{SN}$ metastasis. Consequently, it can be concluded that the combined method involving RI and ICG is more effective than either method alone because it contributes to accurate $\mathrm{N}$ staging. However, the combined method has a drawback compared with either single method. As demonstrated in our data, the combined method tended to identify a larger number of SNs, and as a result, we had to excise a larger number of SNs in this method than in the RI or ICG method. This point is also mentioned in previous reports, and this is obviously because ICG identifies a larger number of SNs $[8,14,15]$. This phenomenon can be attributed, in part, to the size of the colloid particle of the tracer. It is reported that smaller colloid particles can easily pass through lymphatic ducts beyond the first node and spread to other nodes $[16,17]$. The molecular weight of ICG is relatively low; therefore, ICG can easily diffuse and reach more distant lymph nodes, resulting in their identification. The risk of lymphedema increases with an increasing number of resected ALNs. To improve the practicality of the combined method, it would be necessary to further minimize the number of SNs excised with SNB. In this study, we observed that the absence of $\mathrm{SN}(\mathrm{RI})$ is one of the risk factors of ALN metastasis, which could be explained by the low molecular weight of ICG. Since RI usually stays within the first SN, one or two SNs are identified on SNB. If lymph node metastasis is severe, such as stage pN2-3, the afferent and efferent lymphatic tubes of the first SN may already be blocked by tumor cells. Consequently, RI cannot reach the first $\mathrm{SN}$, which may result in negative reactivity. In contrast, the low-molecular-weight ICG reaches the first SN as well as the second and third SNs. Additionally, ICG is known to diffuse to further SNs via a fine network of individual nodes; even if the afferent and efferent lymphatic tubes are occluded by tumor cells, ICG may be able to reach some lymph nodes that cannot be reached by RI. Another possible cause is that the accumulation of tumor cells in SNs increases the internal SN pressure and weakens the retention of radioactive colloid, thus affecting RI detection. However, the actual mechanism remains unclear because there are some cases of absent $\mathrm{SN}(\mathrm{RI})$ even if there is no metastasis. In this study, 2.4\% (8/338) of cases had absent SN(RI). Several clinical factors, such as invasive size, histology type, histological grade, and hormone receptor status, have been reported as predictors of pN2-3 [18-21], but no study has identified the absence of $\mathrm{SN}(\mathrm{RI})$ as a predictor of pN2-3 so far. The absence of $\mathrm{SN}(\mathrm{RI})$ is a valuable risk factor for axillary metastasis that has not been identified in previous studies. Therefore, the combined method, including RI and ICG, not only overlooks pN1 but also contributes to the selection of cases that truly require ALND.

This study had several limitations. First, there were technical differences between SNB procedures performed at each medical facility. Although SNB is a widely established procedure, its accuracy depends to some extent on the skill of the operator and the facility environment. In this study, well-trained breast surgeons performed SNB, and 7 of the 8 cases of absent SN(RI) had no hot spot on lymphoscintigraphy, while one had a weak hot spot, which suggests that SNB was performed accurately. To eliminate the disparity in SNB results between operators and facilities, SNB should ideally be performed according to the same standards in terms of the dose, timing, and site of administration of RI and ICG. Otherwise, the results derived from this study cannot be completely applied to other facilities. Second, the number of 
patients in this study was relatively small and our data were retrospective. Prospective data with a larger number of patients are required to corroborate our findings.

The combined method involving RI and ICG is less likely to overlook SN metastasis than either method alone; therefore, it contributes to the accurate assessment of SN metastasis. The absence of $S N(R I)$ is a rare but significant sign of advanced ALN metastasis, and additional ALND should be strongly considered for accurate nodal staging in such cases.

\section{Declarations}

Acknowledgments: None

\section{Compliance with Ethical Standards}

Disclosure of potential conflicts of interest: The authors have no conflicts of interest to declare.

Ethical approval: All procedures performed in studies involving human participants were in accordance with the ethical standards of the institutional and/or national research committee and with the 1964 Helsinki declaration and its later amendments or comparable ethical standards. The study was approved by the institutional ethics committee of the National Cancer Center Hospital in Tokyo, Japan.

Informed consent: For this type of study, formal consent is not required.

Funding: None.

Conflicts of interest: The authors have no conflicts of interest to declare.

\section{References}

1. Giuliano AE, Ballman KV, McCall L, Beitsch PD, Brennan MB, Kelemen PR et al (2017) Effect of axillary dissection vs no axillary dissection on 10-year overall survival among women with invasive breast cancer and sentinel node metastasis: the ACOSOG Z0011 (Alliance) randomized clinical trial. JAMA 318:918-926

2. Giuliano AE, Hunt KK, Ballman KV, Beitsch PD, Whitworth PW, Blumencranz PW et al (2011) Axillary dissection vs no axillary dissection in women with invasive breast cancer and sentinel node metastasis: a randomized clinical trial. JAMA 305:569-575

3. Kell MR, Burke JP, Barry M, Morrow M (2010) Outcome of axillary staging in early breast cancer: a meta-analysis. Breast Cancer Res Treat 120:441-447

4. Nocera NF, Pyfer BJ, De La Cruz LM, Chatterjee A, Thiruchelvam PT, Fisher CS (2018) NSQIP analysis of axillary lymph node dissection rates for breast cancer: implications for resident and fellow participation. J Surg Educ 75:1281-1286 
5. Sugie T, Kinoshita T, Masuda N, Sawada T, Yamauchi A, Kuroi K et al (2016) Evaluation of the clinical utility of the ICG fluorescence method compared with the radioisotope method for sentinel lymph node biopsy in breast cancer. Ann Surg Oncol 23:44-50

6. Xiong L, Gazyakan E, Yang W, Engel H, Hünerbein M, Kneser U et al (2014) Indocyanine green fluorescence-guided sentinel node biopsy: a meta-analysis on detection rate and diagnostic performance. Eur J Surg Oncol 40:843-849

7. Valiveru RC, Agarwal G, Agrawal V, Gambhir S, Mayilvaganan S, Chand G et al (2020) Low-cost fluorescein as an alternative to radio-colloid for sentinel lymph node biopsy-a prospective validation study in early breast cancer. World J Surg 44:3417-3422

8. Vermersch C, Raia-Barjat T, Chapelle C, Lima S, Chauleur C (2019) Randomized comparison between indocyanine green fluorescence plus ${ }^{99 m}$ technetium and ${ }^{99 m}$ technetium alone methods for sentinel lymph node biopsy in breast cancer. Sci Rep 9:6943

9. Ngô C, Sharifzadehgan S, Lecurieux-Lafayette C, Belhouari H, Rousseau D, Bonsang-Kitzis H et al (2020) Indocyanine green for sentinel lymph node detection in early breast cancer: Prospective evaluation of detection rate and toxicity-The FLUOBREAST trial. Breast J 26:2357-2363

10. Goonawardena J, Yong C, Law M (2020) Use of indocyanine green fluorescence compared to radioisotope for sentinel lymph node biopsy in early-stage breast cancer: systematic review and meta-analysis. Am J Surg 220:665-676

11. Amin MB, Edge SB, Greene FL, Byrd DR, Brookland RK, Washington MK et al (eds) (2017) AJCC Cancer Staging Manual, 8th edn. Springer, New York

12. Harvey JM, Clark GM, Osborne CK, Allred DC (1999) Estrogen receptor status by immunohistochemistry is superior to the ligand-binding assay for predicting response to adjuvant endocrine therapy in breast cancer. J Clin Oncol 17:1474-1481

13. Jimbo K, Kinoshita T, Suzuki J, Asaga S, Hojo T, Yoshida M et al (2013) Sentinel and nonsentinel lymph node assessment using a combination of one-step nucleic acid amplification and conventional histological examination. Breast 22:1194-1199

14. Jung S-Y, Han JH, Park SJ, Lee E-G, Kwak J, Kim SH et al (2019) The sentinel lymph node biopsy using indocyanine green fluorescence plus radioisotope method compared with the radioisotope-only method for breast cancer patients after neoadjuvant chemotherapy: a prospective, randomized, open-label, single-center phase 2 trial. Ann Surg Oncol 26:2409-2416

15. Samorani D, Fogacci T, Panzini I, Frisoni G, Accardi FG, Ricci M et al (2015) The use of indocyanine green to detect sentinel nodes in breast cancer: a prospective study. Eur J Surg Oncol 41:64-70

16. Jinno H, Ikeda T, Matsui A, Kitagawa Y, Kitajima M, Fujii H et al (2002) Sentinel lymph node biopsy in breast cancer using technetium-99m tin colloids of different sizes. Biomed Pharmacother 56(Suppl 1):213s-213s6s

17. Higashi H, Natsugoe S, Uenosono Y, Ehi K, Arigami T, Nakabeppu Y et al (2004) Particle size of tin and phytate colloid in sentinel node identification. J Surg Res 121:1-4 
18. Jimbo K, Kinoshita T, Ogura T, Watase C, Murata T, Shiino S et al (2020) Prediction score model for non-sentinel and four or more nodal metastases using a combined method of one-step nucleic acid amplification and histology in sentinel node-positive breast cancer patients. Eur $\mathrm{J}$ Surg Oncol 46:516-521

19. Katz A, Smith BL, Golshan M, Niemierko A, Kobayashi W, Raad RA et al (2008) Nomogram for the prediction of having four or more involved nodes for sentinel lymph node-positive breast cancer. $\mathrm{J}$ Clin Oncol 26:2093-2098

20. Shimazu K, Sato N, Ogiya A, Sota Y, Yotsumoto D, Ishikawa T et al (2008) Intraoperative nomograms, based on one-step nucleic acid amplification, for prediction of non-sentinel node metastasis and four or more axillary node metastases in breast cancer patients with sentinel node metastasis. Ann Surg Oncol 25:2603-2611

21. Murata T, Watase $C$, Shiino S, Jimbo K, Iwamoto E, Yoshida M et al. Development and validation of a preoperative scoring system to distinguish between nonadvanced and advanced axillary lymph node metastasis in patients with early-stage breast cancer. Clin Breast Cancer 2020;17:S15268209(20)30292-5

\section{Tables}

Table 1. Outcome of sentinel lymph node biopsy results of each method

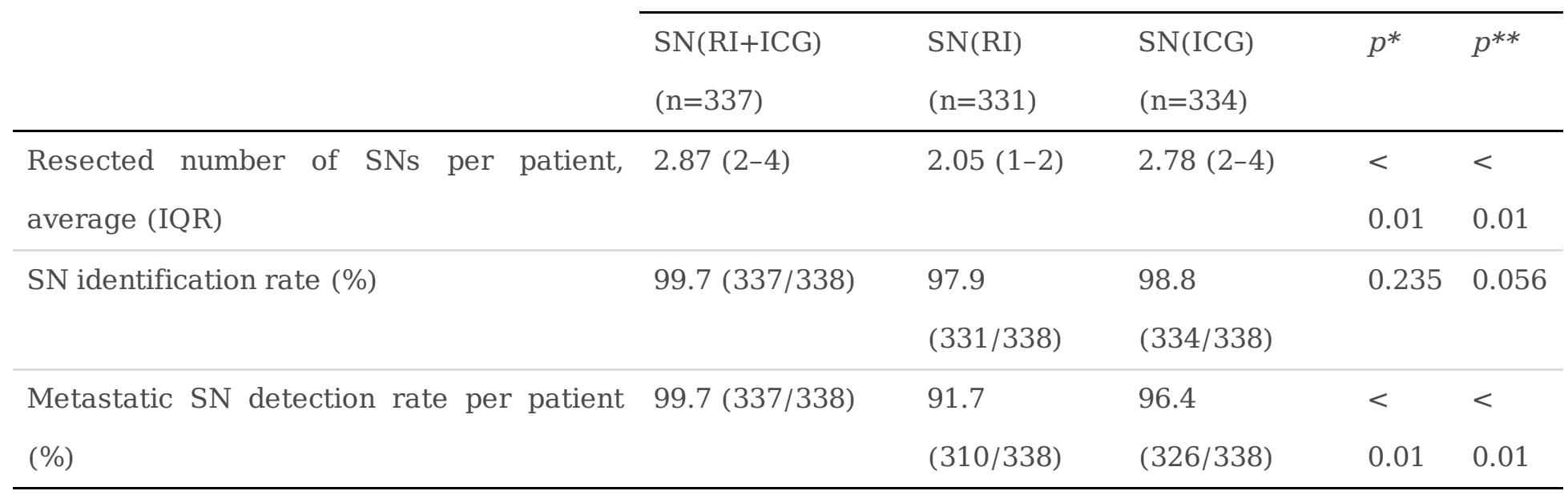

* SN(RI) vs. SN(ICG)

** Comparison between the three methods

In one case, neither SN(RI) nor SN(ICG) was identified.

SN, sentinel lymph node; RI, radioisotope; ICG, indocyanine green; IQR, interquartile range

Table 2. Concordance and discordance rates of metastatic sentinel lymph node detection per patient RI, radioisotope; ICG, indocyanine green; SN, sentinel lymph nodes

Table 3. SN(RI) and SN(ICG) in discordant cases and findings of lymphoscintigraphy

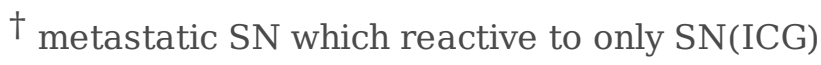




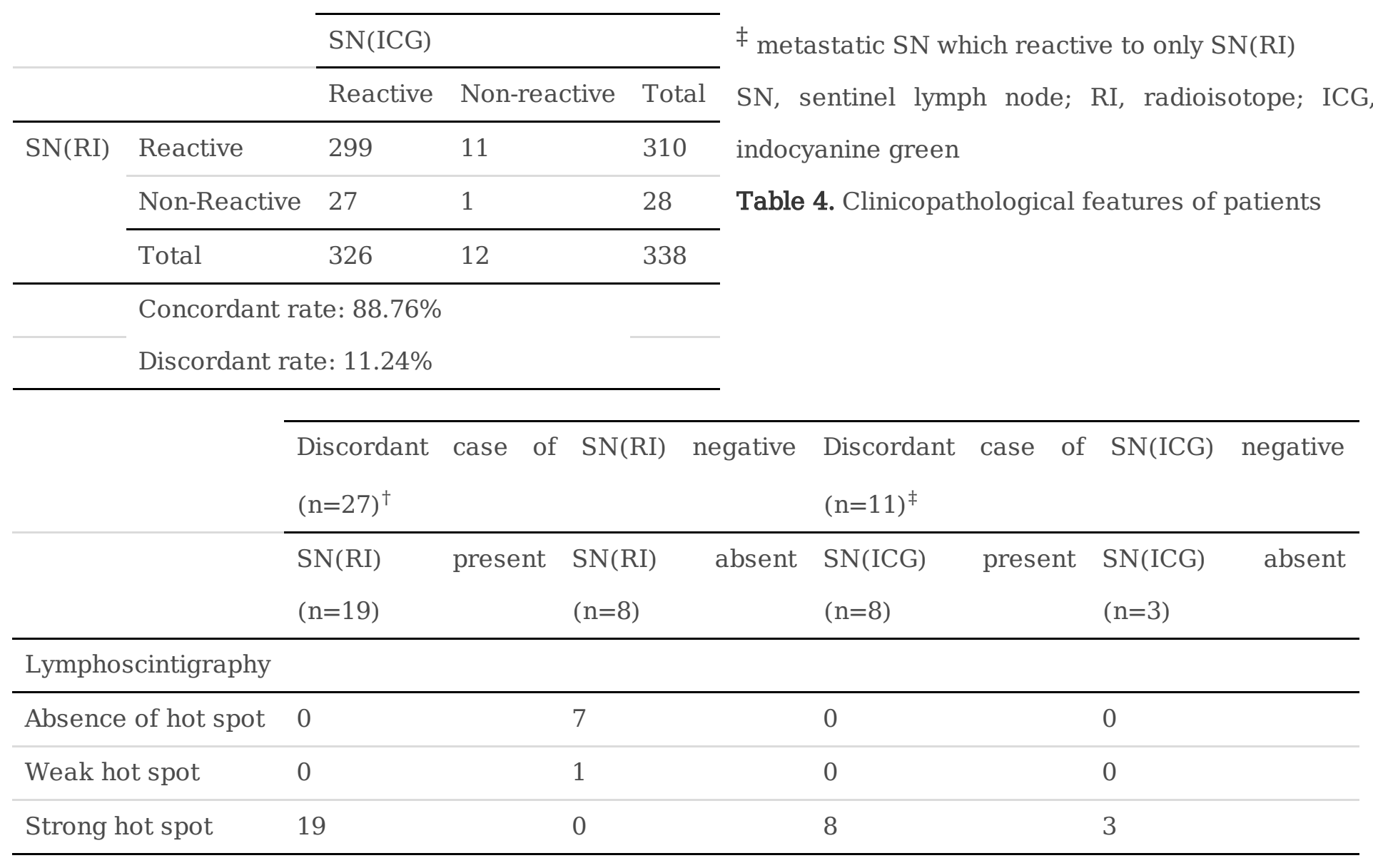




\begin{tabular}{|c|c|c|c|c|}
\hline & \\
\hline & Total ( $\mathrm{n}=338)$ & pN1 (n=276) & $\mathrm{pN} 2-3(\mathrm{n}=62)$ & $p^{*}$ \\
\hline Age (average [range]) & $54.1(29-88)$ & $54.4(29-88)$ & $52.8(30-86)$ & 0.417 \\
\hline \multicolumn{5}{|l|}{ Tumor location } \\
\hline A & 57 & 49 & 8 & \multirow[t]{5}{*}{0.858} \\
\hline B & 21 & 17 & 4 & \\
\hline $\mathrm{C}$ & 187 & 152 & 35 & \\
\hline $\mathrm{D}$ & 44 & 34 & 10 & \\
\hline $\mathrm{E}$ & 29 & 24 & 5 & \\
\hline \multicolumn{5}{|l|}{ Resected number of SNs } \\
\hline$\leq 2$ & 174 & 148 & 26 & \multirow[t]{2}{*}{0.096} \\
\hline$\geq 3$ & 164 & 128 & 36 & \\
\hline \multicolumn{5}{|c|}{ Discordance between SN(RI) and SN(ICG) } \\
\hline No & 300 & 246 & 54 & \multirow[t]{2}{*}{0.647} \\
\hline Yes & 38 & 30 & 8 & \\
\hline \multicolumn{5}{|l|}{$\mathrm{SN}(\mathrm{RI})$} \\
\hline Present & 330 & 273 & 57 & \multirow[t]{2}{*}{$<0.01$} \\
\hline Absent & 8 & 3 & 5 & \\
\hline \multicolumn{5}{|l|}{$\mathrm{SN}(\mathrm{ICG})$} \\
\hline Present & 334 & 273 & 61 & \multirow[t]{2}{*}{0.729} \\
\hline Absent & 4 & 3 & 1 & \\
\hline \multicolumn{5}{|l|}{ cT stage } \\
\hline is or 1 & 161 & 143 & 18 & \multirow[t]{2}{*}{$<0.01$} \\
\hline 2 or 3 & 177 & 133 & 44 & \\
\hline \multicolumn{5}{|l|}{ Histological type } \\
\hline Ductal carcinoma & 287 & 243 & 44 & \multirow[t]{2}{*}{$<0.01$} \\
\hline Special type & 51 & 33 & 18 & \\
\hline \multicolumn{5}{|l|}{ Histological grade } \\
\hline G1 or 2 & 239 & 203 & 36 & \multirow[t]{2}{*}{0.015} \\
\hline G3 & 99 & 73 & 26 & \\
\hline \multicolumn{5}{|l|}{ Type of surgery } \\
\hline Breast conserving & 145 & 129 & 16 & \multirow[t]{2}{*}{$<0.01$} \\
\hline Mastectomy & 193 & 149 & 44 & \\
\hline
\end{tabular}




\begin{tabular}{|c|c|c|c|c|}
\hline $\mathrm{ER}+/$ HER2- & 262 & 217 & 45 & 0.731 \\
\hline $\mathrm{ER}+/$ HER2+ & 40 & 31 & 9 & \\
\hline ER-/ HER2+ & 16 & 13 & 3 & \\
\hline ER-/ HER2- & 20 & 15 & 5 & \\
\hline
\end{tabular}

* pN1 vs. pN2-3

SN, sentinel lymph node; RI, radioisotope; ICG, indocyanine green; ER, estrogen receptor.

Table 5. Multivariate analysis of $\mathrm{pN} 2-3$

\begin{tabular}{|c|c|c|c|}
\hline & \multicolumn{3}{|l|}{$\mathrm{pN} 2-3$} \\
\hline & Odds ratio & 95\% CI & $p$ \\
\hline \multicolumn{4}{|l|}{$\mathrm{SN}(\mathrm{RI})$} \\
\hline \multicolumn{4}{|l|}{ Present $^{\dagger}$} \\
\hline Absent & 8.64 & $1.883-39.639$ & $<0.01$ \\
\hline \multicolumn{4}{|l|}{ cT stage } \\
\hline \multicolumn{4}{|l|}{ is or $1^{\dagger}$} \\
\hline 2 or 3 & 2.549 & $1.345-4.831$ & $<0.01$ \\
\hline \multicolumn{4}{|l|}{ Histological type } \\
\hline \multicolumn{4}{|l|}{ Ductal carcinoma ${ }^{\dagger}$} \\
\hline Special type & 3.276 & $1.625-6.604$ & $<0.01$ \\
\hline \multicolumn{4}{|l|}{ Histological grade } \\
\hline \multicolumn{4}{|l|}{ G1 or $2^{\dagger}$} \\
\hline G3 & 1.921 & $1.032-3.574$ & 0.039 \\
\hline
\end{tabular}

To avoid multicollinearity, type of surgery was excluded in this analysis

$\dagger$ Reference

SN, sentinel lymph node; RI, radioisotope; CI, confidence interval

\section{Figures}



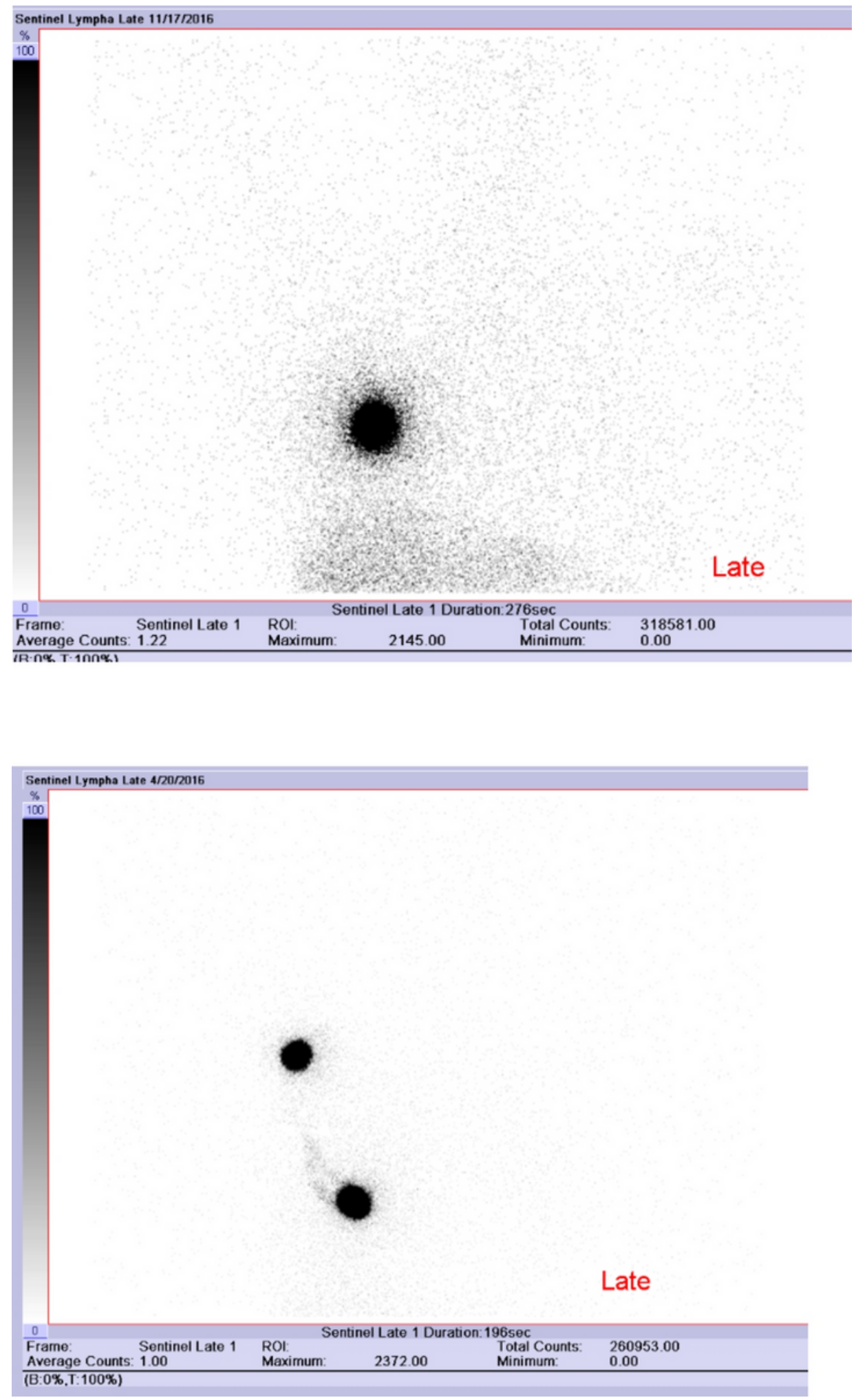

\section{Figure 1}

Finding on lymphoscintigraphy ( $3 \mathrm{~h}$ after radioisotope injection). (a) A hot spot is visible in the peri-areola area but not in the axillary area. (b) Hot spots are visible in the axillary and peri-areola areas 